\title{
Las palabras y las imágenes: la combinación de lenguajes estéticos como rasgo distintivo de nuestro tiempo. Mr Gwyn, escribir retratos
}

\author{
Mirella MAROTTA PÉRAMOS ${ }^{1}$ \\ Universidad Complutense de Madrid \\ marotta@ucm.es
}

Recibido: $10 / 10 / 2014$

Aceptado: 01/11/2014

\section{RESUMEN}

Se empieza analizando una instalación de pintura del autor holandés Jo Heijnen para ver cómo los distintos lenguajes artísticos pueden unirse para crear piezas nuevas. A continuación se estudian las obras de Alessandro Baricco y las mezclas de géneros literarios y estilos que podemos encontrar en ellas hasta llegar a $M r$ Gwyn, donde el autor une la pintura con la narración.

Palabras clave: Alessandro Baricco, géneros literarios, lenguajes estéticos.

The Words and the Images: The Mixture of Aesthetic Languages as a Key Feature of our Times. Mr Gwyn, Writing Portraits

\begin{abstract}
We start by analysing a painting installation by Jo Heijnen ad we study the different artistic languages and how they can cope together for creating new pieces. Then, we study Baricco's works and the mixture of literary genres we can easily spot in his texts. We end by studying $M r G w y n$, where the authorplays mixing words and painting.
\end{abstract}

Key words: Alessandro Baricco, literary genres, aesthetic languages.

Sumario: 1. Introducción 2. La biblioteca de pintura 3. City: La ciudad de los caminos que se entrecruzan 4. Las obras de la primera época: la experimentación con los géneros literarios 5. Una historia particular en una pista de carreras 6. Mr Gwyn: relatos pintados con palabras.

${ }^{1}$ Departamento de Filología Italiana, Facultad de Filología, Ciudad Universitaria s/n, E28040 Madrid, España. 
Scrivere significa tenere insieme il mondo dopo che lo hai fatto a pezzi, e molta della bellezza che noi troviamo nella letteratura proviene da questo.

(Alessandro Baricco, Palladium Lectures)

Para Jo

\section{INTRODUCCIÓN}

Antes de nada, parece necesario inic iar este trabajo dando una explicación sobre la primera parte de su título y el punto desde el que se parte para proponer una lectura de la literatura y el arte de los últimos años. En el título se evoca de forma clara la obra de Michel Foucault, Las palabras y las cosas, que arranca con una reflexión sobre la influencia trascendental que tienen las palabras, o simplemente las letras, en la categorización y comprensión del significado de los objetos. Partiendo de la taxonomía imposible supuestamente encontrada por Borges en una enciclopedia china, Foucault argumenta:

No son los animales «fabulosos» los que son imposibles, ya que están designados como tales, sino la escasa distancia en que están yuxtapuestos a los perros sueltos o a aquellos que de lejos parecen moscas. Lo que vio la cualquier imag inación, cualquier pensamiento posible, es simplemente la serie alfabética $(\mathrm{a}, \mathrm{b}, \mathrm{c}, \mathrm{d})$ que liga con todas las demás cada una de estas categorías. (Foucault 1966 [2010: 8])

Es decir, el absurdo de la relación de animales que «recoge» Borges no radica en que contenga categorías absolutamente heterogéneas y formas de clasificación de muy distinta índole, sino en que todos esos seres se coloquen en una estructura ordenada a través de las letras del alfabeto. Es la unión del objeto (animal en este caso) con las letras lo que desconcierta. Después, Foucault pasará a analizar el cuadro de Las Meninas de Velázquez y nos mostrará, entre otros muchos aspectos, la importancia de los nombres para la comprensión del texto pictórico. La unión de la imagen y la palabra así como la interacción recíproca de ambas: ese será nuestro punto de partida.

Pero hay otro texto más que hemos cogido como base; se trata de Mímesis: las imágenes y las cosas de Valeriano Bozal. Desde la perspectiva del historiador del Arte, Bozal estudia también la relación entre imagen y lenguaje, a la vez que analiza la obra de arte como un texto que casi nos atreveríamos a denominar "narrativo", donde existe un espacio y un tiempo y donde el espectador percibe una historia. Aunque sería muy largo recoger siquiera las ideas fundamentales que aporta Bozal, podemos citar como ejemplo de lo dicho anteriormente el párrafo siguiente: 
Todo representar es un implicar del sujeto. [...] Si la mirada no es un simple deslizar sobre las cosas, si el mirar es atento, [...] entonces podemos hablar de una representación perceptiva en la que la cosa es para un sujeto. Y es en ese ser para un sujeto donde espacialidad y temporalidad se alteran (algunos dirán, se producen) por la simple introducción de un ritmo, cesura que se produce al sacar la cosa del fluir y el ámbito de la facticidad, con lo que la cosa mirada se convierte en figura y posee un significado.(Bozal 1987: 21)

Lo fundamental aquí es ese «un sujeto»; la obra le habla de forma diferente a cada observador y le transmite un contenido propio y casi intransferible, contenido que, como vemos, se articula sobre un ritmo, un tiempo y un espacio. El crítico define la forma significante mínima como figura: «llamaré figura a todo objeto que posee un significado» (Bozal 1987: 21) y añade que tiempo y espacio pertenecen a esta categoría, es decir, son parte de la representación misma: «Representar quiere decir, pues, organizar el mundo fáctico en figuras. El nivel más elemental de esta organización es el espacio temporal, condición y supuesto de cualquier otro más complejo. Ello quiere decir que también espacio y tiempo, lejos de ser datos, se organizan como figuras» (Bozal 1987: 22). Pero también la palabra es parte de esa representación y de esa figura. Tomando como punto de partida el Botellero de Marcel Duchamp, añade:

Cuando se representa al objeto en figura diferente se percibe con claridad la índole de esta articulación: puedo decir que he visto un "botellero" para comprarlo, o puedo decir que he contemplado un "botellero", expresión que a mi presunto interlocutor le resultará extraña, no habitual, y le permitirá adivinar que estoy hablando de un ready-made de Marcel Duchamp. La diferencia lingüística me permite comunicar dos tipos de significado, y figura, para un mismo objeto. (Bozal 1987: 22)

Como podemos ver, es el verbo utilizado el que le transfiere el significado a la figura, a la vez que forma con ella una unidad indisoluble. Si bien en lo que se refiere a la percepción subjetiva de la obra de arte, Bozal no hace sino recoger las tendencias de la crítica de su momento y del concepto de opera aperta, cuando plantea la relación entre la imagen y la palabra, el crítico está siendo innovador y pionero de las nuevas tendencias en la literatura y el arte que pintores y escritores empiezan en ese momento a plasmar en sus obras.

Esto nos lleva a la segunda premisa que debemos establecer antes de iniciar con el anális is: trataremos de definir algunos rasgos especialmente significativos de la Posmodernidad así como el marco en el que se insertan las obras de Alessandro Baricco. Son bien conocidas las teorías críticas sobre esta época así como las distintas escuelas, sin embargo, estamos ante un movimiento heterogéneo y cambiante que, además, ha evolucionado de forma muy rápida desde sus inicios. Precisamente el punto inicial es uno de los temas más controvertidos; autores como Fredric Jameson lo sitúan incluso en la Factory y Warhol. Desde luego, hay grandes diferencias entre los distintos países y entre las distintas artes, pero, por lo que se refiere a Italia y a la literatura, estaríamos hablando de finales de la década de los 
70 y primeros de los 80. Treinta y cinco años «veloci e telematici», como los definió Claudio Piersanti (Piersanti 1989: 88), en los que las obras han evolucionado con la misma rapidez que los tiempos. ¿Qué queda de lo que describieron Lyotard o Jameson? La respuesta es que queda poco, en primer lugar porque escribieron sus obras, que siguen siendo una referencia para todos los que trabajamos sobre este período, antes de que apareciera la mayor parte de la producción literaria que ahora incluimos dentro del período. En segundo lugar, porque pusieron el acento fundamentalmente sobre aspectos sociales, sobre el papel de los autores y sus obras en un momento histórico, dejando casi siempre a un lado el estudio de las obras mismas; nosotros consideramos que, por el contrario, solo a partir del análisis de los textos (literarios o plásticos, eso resulta indiferente) podemos llegar a entender qué ha pasado en las últimas décadas y a valorar las obras que se han creado. En realidad, se podría partir de una definición muy simple de Yuri Lotman, otro crítico de la misma época pero absolutamente vigente precisamente porque centra todo el análisis sobre el texto: «El contenido conceptual de la obra es su estructura» (Lotman 1982 [1970]: 23). Intentaremos demostrar que esta frase resume con una precisión milimétrica la esencia de la literatura del final del siglo XX y del inicio del XXI; los autores harán de la estructura del texto, de su forma, de sus partes, el auténtico contenido. La cita de Baricco de las Palladium Lectures que hemos recogido como inicio de este trabajo es un buen ejemplo de esta forma de pensar: gran parte de la belleza de la obra literaria radica en el conocimiento de su estructura, en la deconstrucción y reconstrucción de nuestro mundo para plasmarlo después en algo nuevo.

Fulvio Panzieri, que ha dedicado gran parte de su trabajo al estudio de este movimiento, se expresa en unos términos muy similares:

Il postmoderno sembra mettere in crisi il rapporto tra le dimensioni: non c'è più distinzione o istituzione di classi di valore tra la letteratura alta e accademica e quella cosiddetta di "genere" o di "consumo". Il tutto è giocato no più all'interno del tessuto linguistico, ma sul piano strutturale. (Panzieri 1996: 33)

También Remo Ceserani, partiendo de las teorías de Jameson y sin negar la importancia que tiene el estudio de la textualidad histórica y el papel de un movimiento en una época determinada, afirma que son los aspectos temáticos y formales los que revelan el imaginario, de manera que resulta prior itario prestar atención a dichos aspectos (Ceserani 2003 [2004: 224]).

Creemos que los textos arriba presentados dejan poco lugar a la duda sobre la importancia de la forma en las obras de estos años. En otros trabajos previos hemos tratado diferentes aspectos formales de las obras italianas de la Posmodernidad; hemos hablado de brevedad y de fragmentación, hemos hablado de rapidez y de "palabra acelerada", y hemos abordado el problema de la mezcla y manipulación de los géneros literarios. La creación de géneros nuevos, más libres, más abiertos y, por ello, más atractivos para los lectores, es sin duda un rasgo esencial a los escritores de este momento. Dice Panzieri: 
Paradossalmente si potrebbe parlare di un postmodernismo usato in funzione ecologica: la letteratura non veicola più l'idea o l'espressione linguistica, ma si fonda sul concetto del «riciclo» delle storie, dei manufatti, dei materiali linguistici, dei generi letterari. (Panzieri, 1996: 37)

Pero, como decimos, hasta aquí, nada que no se haya dicho ya y que nosotros mismos no hayamos analizado en estudios previos. Lo nuevo y casi inesperado es que los autores italianos de los últimos años, y muy especialmente Alessandro Baricco, han dado un paso más allá; han mezclado en sus obras no ya los géneros literarios convencionales, sino lenguajes estéticos provenientes de la arquitectura, la pintura y hasta la ingeniería con la palabra, dando lugar a formas narrativas impregnadas de imagen y de evocación.

\section{LA B IB LIOTECA DE PINTURA}

En 1993 un reconocido pintor holandés, Jo Heijnen, exponía en la Galería Arteara de Madrid la colección A Painters Memory. En la muestra destacaba una imponente instalación que ocupaba una gran pared de la galería de la calle Pintor Rosales: se trataba de una Biblioteca de pintura, en la que grandes acumulaciones de pintura al óleo se presentaban sobre baldas de madera, a modo de estanterías, creadas también por el propio autor; una gran biblioteca en la que los libros, junto con el conocimiento y la experiencia que estos comunican, se hubieran transformado en materia al óleo.

El trabajo de Jo Heijnen se desarrolla en el último tercio del siglo XX en el ámbito de la abstracción pictórica. Para él la elección de lo abstracto suponía una decisión no solo estética sino fundamentalmente ética, a través de la cual su obra adoptaba una sutil toma de posición crítica hacia el entorno. Pero la abstracción de sus cuadros se centra en una nueva concepción y anális is de la materia; emplea la pintura no como representación sino presentación; en sus obras las masas de óleo se transforman prácticamente en objetos cargados de materia. Son coágulos aplicados sobre la superficie de la obra dispuesta en plano y dejados secar, que crean imágenes de carácter orgánico, casi mineral. Las obras del autor surgen como reflexiones sobre la materia y los átomos que la conforman (K. Marotta 2007: 1).

Delante de esa biblioteca de hace veinte años, tuvimos por primera vez la certeza de que la obra de arte abandonaba la tradicional división de lenguajes. Ya no era posible separar la pintura de la escultura, de la arquitectura, de la literatura. Todas estas formas expresivas se iban a ir uniendo para crear algo nuevo, único y vivo. En aquella galería, los sólidos bloques de color sobre las estanterías eran unos libros que contaban su propia historia; el espectador leía en cada uno de ellos experimentando las sensaciones que el autor había querido transmitirle. Todos eran distintos entre sí y se contextualizaban en el seno de las baldas de madera que actuaban casi como un marco y convertían al conjunto en una suerte de colección de cuentos. Por supuesto, las baldas, esa cornice (utilizando el término italiano 
altamente expresivo por la larga tradición que lo enriquece), también habían sido creadas por el artista; eran un elemento más del relato.

El catálogo de la exposición recoge la correspondencia entre la comisaria de la misma y el artista, que escribía desde Ámsterdam. Ella se sorprendía y casi se preocupaba por la acumulación de kilos de óleo que iban llegando: «La galería va a convertirse en un abrumador almacén de materia...». Pero al mismo tiempo, se mostraba consciente de que era el modo en el que el arte encontraba la forma de renovarse y de perdurar:

No dejo de pensar que, trágicamente, no hay más remedio que aceptar la necesidad de que existan nuevas formas, nuevos lenguajes. Ya hace mucho tiempo que el arte se murió, y sin embargo seguimos rebuscando entre las brasas. (K. Marotta1993:sin n. pág.)

\section{Y más adelante:}

La instalación que pretendes hacer, desde que me expusiste el proyecto, y ahora más, cuando lo veo, no deja de parecerme un montón de memoria acumulada. Memoria al óleo que chorrea por las baldas, que se acumula en nudosos grumos de masa gris sobre las tablas de madera. Tengo la imagen de ella como la de una biblioteca del recuerdo en la que nunca existieron unos libros que, en todo caso, se habrían derretido. (K. Marotta 1993: sin n. pág.)

Como hemos visto antes en Bozal, de nuevo tiempo y memoria, elementos de la narrativa que ahora se hacen patentes en una obra plástica. Años después, algunos cuadros posteriores del autor presentarán referencias claras a la naturaleza o al uso cultural de esta, remitiendo a través de campos de color a un terreno sobre el que la gruesa capa de pintura se extiende formando surcos, caminos, líneas con un ritmo y un movimiento que ha hecho pensar a la crítica en un campo arado y que, nuevamente y a pesar de la ausencia total de figuras o imágenes, podrían evocar una historia.

En la pasta gorda y líquida que cubre el cuadro regularmente, se han formado barbas, rebabas y surcos como relieves en los cuales se ha marcado el movimiento de una brocha de cerdas gruesas o quizá una espátula de dientes anchos, conformando una suerte de escritura que parece haber arado toda la superficie del cuadro. (Stempel 2000: 90)

Otra vez encontramos el concepto de escritura asociado a estas obras. Cuadros que son relatos visuales de historias individuales, y materia al óleo que deja de ser simplemente eso para convertirse en metáfora de la realidad. Nos lo explica Bozal con un ejemplo que tiene mucha similitud con el que estamos tratando:

Las piedras y los guijarros de que echó mano Miró estaban presentes en la playa donde los buscaba, pero estaban como la arena y el aire, como el agua, las hierbas y tantos otros guijarros y piedras, formando un conjunto en el que se perdía su condición, su figura. Sólo cuando Miró, al sacarlas de ese horizonte y convertirlas en parte de una 
escultura, supo verlas, sólo entonces se presentaron ante él y ante todos aquellos que gozamos de sus esculturas, de tal modo que ahora ya no podemos ver las piedras con la no-mirada que antes teníamos. (Bozal 1987: 28)

\section{CITY: LA CIUDAD DE LOS CAMINOS QUE SE ENTRECRUZAN}

Al igual que cuando hablábamos de la imagen del tiempo que se derrite en una memoria perdida no podíamos no pensar en la obra de Dalí La persistencia de la memoria (frecuentemente conocido como Los relojes blandos), este espacio físico que habla de memoria, deseo, relaciones, relatos en definitiva, nos lleva directamente a Las ciudades invisibles de Calvino. Allí es la arquitectura la que cuenta la historia, que se lee en las calles, las plazas, las cúpulas de los palacios, las escaleras de caracol; elementos sólidos, físicos que hablan de lo sutil e intangible.

Inutilmente, magnanimo Kublai, tenterò di descriverti la città di Zaira dagli alti bastioni. Potrei dirti di quanti gradini sono le vie fatte a scale, di che sesto gli archi dei porticati, di quali la mine di zinco sono ricoperti i tetti; ma so già che sarebbe co me non dirti nulla. Non di questo è fatta la città, ma di relazioni tra le misure del suo spazio e gli avvenimenti del suo passato: la distanza dal suolo d'un lampione e i piedi penzolanti d'un usurpatore impiccato; il filo teso dal lampione alla ringhiera di fronte e i festoni che impavesano il percorso del corteo nuziale della regina; l'altezza di quella ringhiera e il salto dell'adultero che la scavalca all'alba; l'inclinazione d'una grondaia e l'incedervi d'un gatto che si in fila nella stessa finestra; la linea di tiro de lla nave cannoniera apparsa all'improvviso dietro il capo e la bo mba che distrugge la grondaia; gli strappi delle reti da pesca e i tre vecchi che seduti sul molo a rammendare le reti si raccontano per la centesima volta la storia della cannoniera dell'usurpatore, che si dice fosse un figlio adulterino della regina, abbandonato in fasce lì sul molo. Di quest'onda che rifluisce dai ricordi la città s'imbeve come una spugna e si dilata. (Calvino 1993: 10)

Estamos ya en Baricco y otra vez una ciudad nos cuenta su propio relato; es ella la protagonista del libro, como lo demuestra su propio título: City. Pero la estructura literaria y argumental no es la de la Florencia de Cronache di poveri amanti o de tantas obras del Neorrealismo en las que el espacio impregna de sí las vicisitudes de los personajes. En City la ciudad es la obra narrativa misma, es su esencia, sus partes, sus personajes, su tiempo y sus relaciones. Baricco, como cualquier autor pos moderno, no deja nada al azar, quiere que sus lectores entiendan dónde se encuentran y qué es lo esencial en el texto, así que presenta con estas palabras la obra que está dando a la luz:

Questo libro si intitola City. Mi rendo conto che, dopo Seta, era meglio trovare qualcosa che suonasse un po' diverso. Ma questo libro è costruito come una città, come l'idea di una città. Mi piaceva che il titolo lo dicesse. Adesso lo dice.

Le storie sono quartieri, i personaggi sono strade. Il resto è tempo che passa, voglia di vagabondare e bisogno di guardare. Ci ho viaggiato per tre anni, in City. Il lettore, se 
vorrà, potrà rifare la mia strada. È il bello, e il difficile, di tutti i libri: si può viaggiare nel viaggio di un altro? (Baricco 1999: solapa)

Dejando a un lado el guiño a los lectores sobre la identidad fónica de sus dos libros consecutivos, Seta y City, a la que volveremos un poco más adelante, lo que nos importa aquí es destacar el concepto de libro construido como una ciudad. Es decir, como en la Biblioteca de pintura se unía la materia de la instalación a lo inmaterial de la memoria y el relato, de igual forma en City se une lo físico y arquitectónico de los barrios y las calles a lo intangible de las historias y los personajes. Las partes de la ciudad establecen las relaciones sintagmáticas y paradigmáticas del texto. En toda ciudad hay barrios de distinta naturaleza; así, la similitud de su obra con una ciudad real permite al autor construir historias muy diferentes, situadas en tiempos y espacios distintos; incluso diseña «un paio di quartieri, in City, che scivolano indietro nel tempo. In uno c'è una storia di boxe, ai tempi della radio. Nell'altro c'è un western» (Baricco 1999: solapa). El resto, como en Le città invisibili y como Calvino dejaría anotado en su testamento para la nueva generación de escritores, Sei proposte per il prossimo millennio, es tiempo, viaje y observación.

Al hablar de esta nueva forma de entender el espacio, no podemos no acudir a Fredric Jameson y a su excelente capítulo «El postmodernismo y la ciudad», en el que casi parecería que se hubiera inspirado Baricco para construir la suya:

Así pues, la arquitectura más reciente -al igual que muchos de los productos culturales arriba evocados- representa una suerte de exhortación a que desarrollemos nuevos órganos, a que ampliemos nuestra sensibilidad y nuestro cuerpo hasta alcanzar dimensiones nuevas, todavía inconcebibles y quizás, en última instancia, imposibles. (James on 1996 [1984]: 58)

\section{LAS OBRAS DE LA PRIMERA ÉPOCA: LA EXPERIMENTACIÓN CON LOS GÉNEROS LITERARIOS}

Hemos empezado viendo el juego y la manipulación de lenguajes artísticos que Baricco lleva a cabo en City por ser esta una excelente heredera de Calvino; pero, cronológicamente, hay otras obras anteriores del autor en las que ya aparecía una clara mezcla de estilos. Estamos todavía dentro de un único lenguaje estético, el literario; Baricco inicia la experimentación sobre lo que debe ser la nueva narrativa uniendo distintos géneros literarios, solo más adelante se atreverá con "mezclas" más radicales, como la arquitectura y la narrativa, en el ejemplo que acabamos de ver, las 18 curvas de un circuito de carreras y la historia de una vida en Questa storia, o los retratos y el relato breve en $M r G w y n$, que es el texto al que pretendemos llegar y cuyo análisis nos proponemos acometer. Pero creemos que es importante ir recorriendo una a una las fases de este proceso en el que el autor se fue sintiendo poco a poco más libre y capaz de ir uniendo e imbricando elementos cada vez más dispares. 
Filippo La Porta, al hacer una especie de catálogo de los autores italianos posmodernos a muy pocos años del fin de siglo, consideraba que es precisamente esa capacidad que tiene Baricco de unir lenguajes heterogéneos lo que lo convierte en un referente dentro de su generación:

Proprio Baricco, senza cedere alle lusinghe di una letteratura di facile consumo o a una facile spettacolarità, persegue una propria personale ricerca di postmoderno d'autore, nel senso di una contaminazione letteraria molto colta (con un rifacimento-parodia di alcuni modelli), apparentemente centrifuga, anarchica, ma incorniciata da una "musica" stregante e assai riconoscibile (come scandita da quello strano strumento che nel primo romanzo si chiama «umanofono»). (La Porta 1995: 83)

Desde luego, él no es el único autor que hace este experimento. Antonio Tabucchi, al que hemos dedicados otros estudios, es sin duda uno de los maestros, $\mathrm{y}$, en general, la mayor parte de los escritores que han venido publicando desde los años 90 del siglo XX hasta este momento han trabajado en la misma línea. Tabucchi incluso aborda esta característica de la literatura de su tiempo en una conversación / entrevista con Paola Gaglione y Marco Cassini. Ante la pregunta de los críticos, «Se pensiamo invece al futuro, a questa grande trasformazione del romanzo di cui lei parlava, che tipo di evoluzione vede per questo genere?», el autor responde:

Io credo che quello che possiamo costatare è una caduta fortissima fra le divisioni dei vari generi letterari.

[...] il testo letterario ha acquisito una autonomia tale per cui è un organis mo indipendente. Equesta evoluzione graduale sta avvenendo in tutta l'Europa e anche al di là dei confini europei.

Gli antichi avevano scoperto le muse, noi oggi abbiamo capito che le muse, forse divise per categoria non esistono più.

C'è una musa unica, magari un po' zoppa e un po' sindacalizzata che ci assiste tutti; assiste lo scrittore di libretti d'opera, come assiste lo scrittore di testi teatrali, come assiste nelle sue manchevolezze il romanziere.

$[\ldots]$

Io credo che l'arte in tutte le manifestazioni oggi abbia degli aspetti molto simili: non mi sento molto lontano da un architetto, non mi sento molto lontano da un pittore, da un musicista, [...]. (Gaglione, Cassini 1997: 11-12)

Como puede verse por estas palabras, el autor tiene muy claro que si algo puede dar nueva vida a esa novela cuya muerte habían anunciado los escritores de los $50 \mathrm{y}$ de los 60, es la renovación de los géneros y de los lenguajes estéticos en una nueva obra más abierta y más libre.

Baricco partía ya con ventaja, puesto que antes de convertirse en escritor había iniciado su carrera artística como músico. La música es la auténtica protagonista de su opera prima, Castelli di rabbia, tanto como elemento temático como, muy especialmente, por el ritmo que se siente en cada frase del texto; es un ritmo continuo, 
acelerado, que procede a borbotones, como un río y como una fuga barroca. Si las pasiones son la esencia de esta increíble novela, la música es su alma.

Pero donde el autor realmente inicia el juego de mezcla y manipulación de géneros literarios es en Novecento, en 1994. Y pocas veces el término "juego" está tan justificado. El autor empieza poniendo un subtítulo a su texto: Un monologo, con lo que está ya llamando la atención del lector sobre el hecho de que el género en el que se inserta su obra es un dato relevante pero, al mismo tiempo, que vamos a estar ante una de esas formas híbridas por definición. El monólogo se sitúa siempre en un terreno incierto, a caballo entre el teatro y la narración breve. Y eso será lo que el autor exponga en el prólogo o nota que precede al texto y en el que, debemos repetirlo una vez más, juega con sus lectores. La nota es un prodigio de conocimiento profundo de los mecanismos de la literatura:

Ho scritto questo testo per un attore, Eugenio Allegri, e un regista, Gabriele Vacis. Loro ne hanno fatto uno spettacolo che ha debuttato al festival di Asti nel luglio di quest'anno. Non so se questo sia sufficiente per dire che ho scritto un testo teatrale: ma ne dubito. Adesso che lo vedo in forma di libro, mi sembra piuttosto un testo che stia in bilico tra una vera messa in scena e un racconto da leggere ad alta voce. Non credo che ci sia un nome, per testi del genere. Comunque, poco importa. A me sembra una bella storia, che valeva la pena di raccontare. E mi piace pensare che qualcuno la leggerà. (Baricco 1994: 7)

Nos dice al principio que el texto ha sido ya representado, con lo que el lector decodifica según los parámetros clásicos y lo sitúa en el género teatral; pero rápidamente añade que las cosas no están tan claras y da la definición que sí es real: «un texto que se encuentra a caballo entre una puesta en escena auténtica y un cuento para ser leído en voz alta». Es, en definitiva, una historia que valía la pena ser contada y desea que alguien lea. Es decir, tenemos todos los elementos en igualdad de condiciones: la representación ante un público, la narración en voz alta y la lectura silenciosa y solitaria. En ningún momento Baricco da nombres o etiquetas, y de hecho, dice que no cree que existan para un caso como este; habla siempre de «testo» y de «racconto», los términos más neutros para definir la forma y el contenido de este precioso monólogo.

Podemos simplemente añadir que, como libro, en 1999 Feltrinelli publicaba la vigésimo octava edición, lo que demuestra la gran acogida que recibió por parte de los lectores; que se ha representado en diferentes ocasiones en distintos países; que se han hecho lecturas públicas, una de las cuales estuvo a cargo de Leonor Walting; y, por último, que Giuseppe Tornatore realizó en 1998 la película La leggenda del pianista sull'oceano con el guión adaptado por el propio Baricco. Todo ello no hace más que abundar en la idea de que es un texto perfectamente híbrido y, como tal, perfectamente posmoderno.

Después de Novecento, el autor publica Seta; esta vez la obra nace de la mezcla de prosa y poesía. Seta es un poema épico que habla de un viaje cíclico que se repite hasta en cuatro ocasiones. Los dos elementos formales más sobresalientes 
son la repetición y el ritmo, es decir, los dos principios constitutivos del verso, como explica Lotman de forma magistral:

[...] el texto artístico se construye sobre la base de dos tipos de relaciones: cooposición de elementos equivalentes que se repiten y cooposición de elementos contiguos (no equivalentes).

El primer principio [...] es el principio de repetición, de ritmo. Nivela aquello que en la lengua natural no se halla nivelado.

El segundo principio [...] se trata del principio de metáfora. Combina aquello que en la lengua natural no puede ser combinado. [...]

Se puede interpretar la tendencia a la repetición como un principio constitutivo del verso, la tendencia a la combinación como un principio constitutivo de la prosa. (Lotman 1982 [1970]: 106)

Determinadas partes se repiten en el texto hasta convertirse en estribillo de la composición. Desde la primera página, la obra se presenta ya, incluso desde el punto de vista visual, como un poema; los blancos adquieren un papel trascendental. Veamos el inicio para que pueda entenderse con más claridad a lo que nos referimos:

Benché suo padre avesse immaginato per lui un brillante avvenire nell'esercito, Hervé Joncour aveva finito per guadagnarsi da vivere con un mestiere insolito, cui non era estraneo, per singolare ironia, un tratto a tal punto amabile da tradire una vaga intonazione femminile.

Per vivere, Hervé Joncour comprava e vendeva bachi da seta.

Era il 1861. Flaubert stava scrivendo Salammbô, l'illuminazione elettrica era ancora un'ipotesi e Abramo Lincoln, dall'altra parte dell'Oceano, stava combattendo una guerra di cui non avrebbe mai visto la fine.

Hervé Joncouraveva 32 anni.

Comprava e vendeva.

Bachi da seta. (Baricco 1996: 7)

Si bien el primer párrafo está claramente escrito en prosa, en seguida nos damos cuenta de la repetición de la frase principal, («Hervé Joncour comprava e vendeva bachi da seta») frase que, además, se parte en "versos" aislados como cierre del capítulo. Hay que destacar que este se reduce a las pocas líneas que hemos recogido más arriba, lo que demuestra que brevedad y fragmentación son otros de los elementos que definen a la obra. Evidentemente, si la repetición se limitara a este ejemplo, estaríamos hablando de un caso aislado poco significativo, pero no es así. El capítulo 2 empieza de nuevo retomando la misma frase: «Per la precisione, Hervé Joncour comprava e vendeva i bachi quando il loro essere bachi consisteva nell'essere minuscole uova...» (Baricco 1996: 8). Es la tercera vez; la repetición no puede ser exacta sin que se convierta en automática en la mente del lector y deje de ser efectiva, hace falta un cambio que llame la atención a la vez que se debe seguir insistiendo sobre la misma idea. 
Baricco hará el mismo ejercicio en muchas otras ocasiones: unas veces retomará una frase volviéndola a escribir de forma idéntica, por ejemplo, el capítulo 11 inicia nuevamente con el desconcertante párrafo que sirve para centrar la obra en el tiempo y el espacio: «Era il 1861. Flaubert stava scrivendo Salammbô, l'illuminazione elettrica era ancora un'ipotesi e Abramo Lincoln, dall'altra parte dell'Oceano, stava combattendo una guerra di cui non avrebbe mai visto la fine» (Baricco 1996: 21); y otras, dividirá el párrafo en líneas brevísimas y llenas de ritmo, como auténticos versos, por ejemplo, en el cierre del capítulo 2:

Lavilledieu era il nome del paese in cui Hervé Joncour viveva.

Hélène quello di sua moglie.

Non avevano figli. (Baricco 1996: 8)

Pero la repetición más sorprendente del texto, y la que lo convierte en un auténtico poema épico, es la descripción de los cuatro viajes a Japón. Son relaciones largas, minuciosas, como en todo relato de viajes, llenas de datos, encuentros y paradas; en un texto de capítulos tan breves como hemos visto, los viajes constituyen las partes más largas... y son absolutamente idénticos: 18 líneas densas y de una extraordinaria lentitud en las que cambia solo una palabra: el nombre que las gentes del lugar dan al lago Bajkal. Según avancen los viajes, y con ellos la historia de amor, sueños, deseos, pasiones, el lago irá cambiando de nombre: «mare» / «demonio» / «ultimo» / «santo».

El final es de una belleza perfecta. La última frase ya se había adelantado unas páginas antes y no había pasado desapercibida:

Ogni tanto, nelle giornate di vento, Hervé Joncour scendeva fino al lago e passava ore a guardarlo, giacché, disegnato sull'acqua, gli pareva di vedere l'inspiegabile spettacolo, lieve, che era stata la sua vita. (Baricco 1996: 93)

Frase que, al repetirse como cierre de la obra, simplemente elimina el nombre del protagonista, como si su imagen se desvaneciera con el movimiento del agua, y se transforma en:

Ogni tanto, nelle giornate di vento, scendeva fino al lago e passava ore a guardarlo, giacché, disegnato sull'acqua, gli pareva di vedere l'ins piegabile spettacolo, lieve, che era stata la sua vita. (Baricco 1996: 100)

Es cierto que la mezc la de géneros literarios es más evidente en Novecento, pero no es posible analizar Seta sin encontrarse una y otra vez con los rasgos estructurales del texto poético. Como tal, esta obra se articula mucho más claramente sobre el eje paradigmático que sobre el sintagmático, ya que, como en el verso, cada elemento se ve reforzado y enriquecido por otro que aparece más adelante. Baricco es un autor controvertido, que despierta pasiones encendidas en unos lectores y odios igualmente encendidos en otros; pero lo que no puede negarse es que conoce los mecanismos del texto artístico como muy pocos y que es capaz 
de llevar sus juegos hasta las últimas consecuencias. Veíamos que en la presentación de City, la obra que sigue a esta, decía, haciendo un guiño evidente a sus lectores, que se daba cuenta que, después de Seta, el nombre City resultaba demasiado repetitivo. Otra vez el concepto de repetición, pero ahora todavía un paso más allá:

$$
\text { [seta] [siti] }
$$

como dos palabras-rima en un poema único y completo en el que las obras del autor son estrofas, versos de una misma composición.

\section{UNA HISTORIA PARTICULAR EN UNA PISTA DE CARRERAS}

Hemos analizado solo dos libros de la etapa inicial del autor, los más representativos, a nuestro modo de ver, en lo que se refiere a la mezcla de géneros literarios. También podríamos haber visto el experimento de Omero, Iliade, donde transforma el poema épico en una especie de colección de cuentos con un marco único, la guerra, en el que cada personaje cuenta su propia historia y su propia tragedia; o I Barbari, que inicia directamente con una negación que nos sitúa en el mismo ámbito de reflexión sobre la literatura: «Non sembra, ma questo è un libro» (Baricco 2006: 7) y donde bromea con sus lectores sobre si es una novela, una novela por entregas, un ensayo. Son muchas, prácticamente todas, las obras del autor en las que encontramos manipulaciones de la palabra y de las estructuras formales. Pero el objetivo de este trabajo es ir más allá para ver cómo, después de haber experimentado con los géneros, decide dar un paso adelante y mezclar lenguajes estéticos, hacer lo que veíamos al principio en la Biblioteca de pintura y a lo que se refería Tabucchi cuando decía que el arte en todas sus manifestaciones tiene características muy similares y que no es distinta la musa que asiste al escritor de la que asiste al arquitecto o al pintor.

Sin embargo Tabucchi, a pesar de haber expresado esta idea de forma teórica, no llegó nunca a crear una obra en la que se fundieran estos distintos lenguajes. Baricco sí, y en dos ocasiones, de momento. La primera vez fue en Questa storia, con resultados de una gran belleza. El texto es un paseo por el siglo XX y por las vidas de dos personajes, Ultimo Parri y Elizeveta Seller, destinados a quererse profundamente sin llegar nunca a conseguir que sus caminos permanezcan unidos. En realidad, estamos ante una novela histórica de vidas particulares, otra nueva mezcla de géneros propia del autor. Simplemente este elemento habría sido ya sufic iente para ver que estamos ante uno de los géneros nuevos y diferentes creados por Baricco; se percibe en todo momento la presencia de Elsa Morante y su obra $\mathrm{La}$ Storia, pero ahora es un momento literario nuevo. En este caso, recurrimos a las palabras de Giovanni Vattimo, que pone de manifiesto en qué consiste ese cambio sustancial: 
Pues bien, en la hipótesis que yo propongo, la modernidad deja de existir cuando -por múltiples razones- desaparece la posibilidad de seguir hablando de la historia como una entidad unitaria. [...] No existe una historia única, existen imágenes del pasado propuestas desde diversos puntos de vista, y es ilusorio pensar que exista un punto de vista supremo, comprehensivo, capazde unificar todos los demás. (Vattimo 1994 [1990]: 11-12)

Vattimo define la Posmodernidad como el movimiento que nace cuando la Modernidad ha concluido, y añade que lo que pone de manifiesto esa muerte de lo anterior es el hecho de que ya no exista una Historia (única y con mayúscula) sino que tengamos que conformarnos con otra mucho más pequeña y subjetiva, individual. Baricco nos contará de nuevo la historia de Italia del último siglo, pero no podrá contarnos lo que sintieron todos los hombres y mujeres; podrá contarnos los que sintieron solo dos, y especialmente particulares e irrepetibles.

Decíamos que esto ya habría sido suficiente para convertir a Questa storia en un perfecto exponente de la Posmodernidad, pero el autor todavía tenía un nuevo recurso formal con que sorprender a sus lectores; el final le da una vuelta inesperada a los acontecimientos y a la estructura del texto: años después de la muerte de Ultimo, cuando Elizeveta había perdido la esperanza de legar a entender qué sintió él hacia ella y por qué se fue sin una palabra, un plano para la construcción de una pista de carreras de 18 curvas llega a sus manos. Ultimo lo había dejado para ella entregándolo a la casualidad y a una serie de indicios que la habrían llevado, si la suerte lo permitía, a encontrarlo. Ella manda construir la pista siguiendo fielmente las indicaciones de Ultimo. Por fin puede montarse en un coche y comprender todo lo que nunca se dijo. Cada curva, cada recta, cada aceleración, cada frenada, explican la historia de los sentimientos de Ultimo, una historia que no existe en palabras sino solo en la disposición de ese espacio que les pertenece a ellos. Son dos páginas extraordinarias en la que Baricco retoma todo lo que habíamos visto en el libro, pero antes éramos espectadores, lectores que no sabíamos ni entendíamos lo que pasaba por la mente de un personaje rico y complejo; ahora nosotros, como Elizeveta, conseguimos entender. No vamos a recoger aquí el texto completo, a pesar de ser breve, pero sí las últimas líneas, que demuestran perfectamente cómo esa pista cuenta su historia:

Cominciò a girare, l'automobile, per un tempo che nessuna lancetta misurò mai. Elizeveta non contò quante volte vide il rettilineo d'arrivo, ma si accorse che a poco a poco quel che Ultimo aveva cercato spesso di spiegarle, stava succedendo. Sentì ogni curva sciogliersi gradualmente nell'ordine illogico di un unico gesto, e trovò nella propria mente il cerchio che non esisteva se non per lei. Nel cuore della velocità trovò la perfezione di un semplice anello. Pensò allora all' infinito caos di ogni vita, e a all'arte sopraffina delle cose che sanno pronunciarlo in un'unica figura, compiuta. E capì cosa ci commuove nei libri, nello sguardo dei bambini e negli alberi solitari, in mezzo alla campagna. Quando si accorse di essere scesa nel segreto di quel disegno, chiuse gli occhi, vide gli occhi di Ultimo, sorrise. Poi appoggiò una mano sul braccio del ragazzo che guidava. L'automobile rallentò come se si fosse staccata dall'invisibile forza che fin lì l'aveva trascinata. Percorse sulla spinta ancora due curve, che tornarono, in quella 
antica lentezza, a sembrare curve. Poi, giunta sul rettilineo, la macchina si fermò. (Baricco 2005: 274-275)

\section{MR GWYN: RETRATOS PINTADOS CON PALABRAS}

Mr Gwyn es ya de principio a fin una obra centrada en la mezcla de lenguajes estéticos. El propio tema de la novela es el deseo de un escritor de dejar de escribir de la forma tradicional para convertirse en algo distinto. Jasper Gwyn es un autor de éxito, con un público fiel que lo sigue obra a obra y un editor que lo venera, y no solo porque es un auténtico amigo, sino porque obtiene pingües beneficios con sus libros. Pero un día Jasper Gwyn se levanta con la absoluta determinación de que hay cincuenta y dos cosas que no va a volver a hacer; con la lista de estos propósitos publica un artículo en el/The? Guardian.

L'artico lo consisteva in una lis ta di c inquantadue cose che Jasper Gwyn si prometteva di non fare mai più. La prima era scrivere articoli per il "Guardian". La tredicesima era incontrare scolaresche fingendosi sicuro di sé. La trentunesima, farsi fotografare con la mano sul mento, pensoso. La quarantasettesima, forzarsi di essere cordiale con colleghi che in verità lo disprezzavano. L'ultima era: scrivere libri. In certo modo chiudeva il vago spiraglio che poteva aver las ciato la penultima: pubblicare libri. (Baricco 2011: 9)

Es el pretexto a partir del cual se desarrolla la acción. Resulta evidente que el propósito primero, junto con los dos últimos, de jan al conocido escritor sin ninguna posibilidad de seguir haciendo lo que sabe y le gusta: escribir y publicar. Al principio se siente bien y hasta liberado, pero pronto empieza a echar de menos el «gesto dello scrivere, e la quotidiana cura con cui metteva in ordine pensieri nella forma rettilinea di una frase» (Baricco 2011: 16). Entonces decide que debe dedicarse a algo que esté relacionado con la escritura pero que no sea literatura. Se le pasa por la cabeza escribir guías de viaje y también convertirse en traductor; ambos recursos nos hacen pensar en precedentes literarios fundamentales para los autores de finales del siglo XX y principios del XXI: el primero nos recuerda nuevamente la influencia de Calvino con Le città invisibili, el segundo el experimento de Tabucchi con Requiem, obra que escribe en portugués para que, por una vez, sus lectores italianos reciban un texto traducido y no en la lengua de origen. La intertextualidad en este inicio de Mr Gwyn es muy importante, como podemos comprobar; pero Baricco quiere hacer algo que ningún otro autor ha hecho todavía y decide que su personaje opte por convertirse en copista.

Nos preguntamos, ¿copista de qué? Acabamos de hablar de intertextualidad y de maestros; ahora estamos en plena fantasía pirandelliana: un personaje irreal y absurdo, «Una signora anziana, con un foulard impermeabile in testa» (Baricco 2011:21) que, además, morirá a lo largo de la obra pero que nunca dejará de hablar al protagonista, le dice que lo que tiene que hacer es copiar a la gente, hacer retratos de personas pintados con palabras. Filipppo La Porta, al estudiar las obras de 
Baricco, destaca que « Si affollano lungo tutto il romanzo personaggi e dialoghi e trame in cerca d'autore» (La Porta 1995: 84); sin duda la señora del foulard es uno de esos personajes pirandellianos que pueblan las páginas de este autor posmoderno y que rinden un merecido homenaje al maestro.

El concepto de copista, tal y como se lo explica la señora a Jasper Gwyn, contiene en sí mismo la mezcla de lenguajes artísticos y de formas expresivas; la idea es muy compleja y el lector, como los propios personajes, tarda mucho tiempo, incluso prácticamente toda la obra, en entender realmente a qué se refieren Baricco y la señora del foulard impermeable en la cabeza; se duda, sobre todo, de si esa mezcla existe realmente y de si el autor será capaz de convencernos. Dudábamos en vano. Igual que fue capaz de hacernos vivir toda la vida de Ultimo Parri en las vueltas de una pista de carreras, al final los lectores y los personajes a los que $\mathrm{Mr}$ Gwyn hace los retratos sentimos asombrados que estamos ante una nueva forma de arte, más intensa y viva que la propia pintura o la sola narrativa.

Pero no debemos adelantar acontecimientos. Estamos todavía en el momento inicial, en el momento en el que ni siquiera Jasper Gwyn sabe a qué se refiere el personaje que lo anima a hacer algo tan extraño. La respuesta la obtiene, como no, en una galería de arte. Allí ve una serie de cuadros, todos de gran formato, todos iguales, como si fueran repeticiones hasta el infinito de figuras desnudas en un espacio también desnudo. Luego se fija en una serie de fotografías, entre las cuales una del propio pintor: «Jasper Gwyn ci vide un tempo che non si aspettava, lo scorrere del tempo» (Baricco 2011: 30). Las fotos se han convertido en relatos, relatos con un tiempo que avanza y que pasa. La idea está ya casi completa; los retratos -bien pintados, bien captados con una cámara- poseen la primera condición de la literatura: el tiempo; ahora necesitan las palabras. La galerista se acerca a Jasper Gwyn y le pregunta si le gustan los cuadros:

- No, disse. Non mi piacciono mai i quadri.

- Ah, disse la gallerista.

(...)

- Sono muti, disse.

- Prego?

- Non mi piacciono i quadri perché sono muti. Sono come persone che parlano muovendo le labbra, ma non si sente la voce. (Baricco 2011: 33)

En ese momento el personaje entiende lo que quiere hacer, quiere escribir retratos. A su editor, que muy contento le dice que no le parece mal, que eso también les dará dinero a los dos porque cualquier cosa que publique de él se venderá sin problema, el escritor responde que se equivoca, que se publican los libros, no los cuadros (por más que las pinceladas sean palabras); que un retrato es una obra que alguien encarga al artista y que luego tiene en su casa, para su disfrute personal, «che la gente avrebbe portato a casa quelle pagine scritte, e se le sarebbe 
tenute chiuse in un cassetto, o appoggiate su un tavolo basso. Come avrebbe potuto tenere una fotografia, o appendere un quadro alla parete» (Baricco 2011: 38).

Probablemente la parte más bonita de la obra es la que se dedica a los preparativos para configurar el estudio del artista, un estudio amplio, vacío, con apenas una cama, una silla y las propias manchas de aceite de las paredes, al final de Marylebone High Street. Lo que debe vestir este espacio es solo música y luz, pero realmente especiales. Primero encarga sesenta y dos horas de música que, literalmente, forre el estudio.

E spiegò che quel che gli sarebbe piaciuto era un fondale sonoro in grado di mutare come la luce durante il giorno, e quindi in maniera impercettibile e continua. Soprattutto: elegante. Questo era molto importante. Aggiunse anche che avrebbe voluto qualcosa in cui non c'era ombra di ritmo, ma solo un divenire che sospendesse il tempo, e semplicemente riempisse il vuoto di un trascorrere privo di coordinate. Disse che gli sarebbe piaciuto qualcosa di immobile come un volto che invecchia. (Baricco 2011: 47)

Si en el caso de la música, cuya base es el tiempo, este tiene que desaparecer, para la luz, en cambio, deberá ser la propia esencia. Al Maestro de Camden Town le encarga unas pequeñas bombillas que duren exactamente 32 días luciendo cuatro horas al día; 18 bombillas colgadas del techo, a distancia regular unas de otras, que empiecen a fundirse después de treinta y dos días, una a una, en un lapso de tiempo no inferior a dos días y no superior a una semana. El maestro de Camden Town comprendió perfectamente y eligió las «Caterina de’ Medici, perché sembravano lacrime sfuggite a un lampadario» (Baricco 2011: 51).

El resto es silencio y desnudo. Nuevamente, como en Questa storia y como de alguna manera en todas las obras de Baricco, habrá un amor profundo y distinto entre dos personas destinadas a vivirlo sin nunca encontrarse, sin converger. Después, la irrupción del caos que cambia el curso habitual de los acontecimientos; y tiempo que pasa, preguntas que quedan en suspenso. El caos es elemento esencial en las obras de la Posmodernidad; uno de los filósofos españoles más importantes de estos años, Daniel Innenarity, lo define como «la irrupción de lo inesperado» (Innenarity 2001 [2008: 18]) y añade:

La visión contemporánea del mundo tiende a desembarazarse de aquellas concepciones que lo veían fundamentalmente como una realidad poderosa. La ciencia ha abandonado su rígido determinis mo para manejar unas nociones que tienen que ver con la contingencia, como el caos, la indeterminación o el desorden. (Innenarity 2008: 25)

Para la contraportada de Castelli di rabbia, Baricco eligió una frase que podría valer para describir en dos líneas toda su producción literaria: «Accadono cose che sono come domande. Passa un minuto, oppure anni, e poi la vita risponde» (Baricco 1991: contracubierta). La respuesta a las preguntas que quedaron sin responder después de que el caos irrumpiera en la vida de los dos protagonistas, muchos años después, la darán los propios retratos. Jasper Gwyn no pudo evitar publicarlos, ningún escritor es capaz de no dar a la luz sus obras, o al menos una parte de ellas; 
él publica solo dos, y para ello Baricco y Jasper Gwyn encuentran una forma extraña, barroca, pero perfecta. El primero, el que le hizo a Rebecca y con el que empezó todo, aparece en un libro de una escritora de nove las comerciales y ligeras. Al principio Rebecca se enfada porque piensa que Jasper Gwyn le dio algo copiado, plagiado; pero en seguida se da cuenta de que la realidad es mucho mejor y más elaborada: la Rode, la escritora de cuyos libros habían hablado muchas veces, era, en realidad, el propio Gwyn. Desde el punto de vista de la tradición literaria, estamos ahora en la esfera de Pessoa y de los heterónimos: Baricco nos ha ido mostrando a sus maestros, no podía olvidarse de este.

El siguiente retrato es uno que Rebecca, la ayudante del escritor y la depositaria de una copia de cada una de las obras, no conocía. También esto la enfada al principio y le produce una triste sensación de traición, pero no tiene más que leerlo para reconocer a la persona retratada: es el propio Gwyn; se encuentra ante el autorretrato del pintor, ¿cómo no? Baricco no va a dejar de dar vueltas a la literatura y al arte, buscando un resultado cada vez más nuevo y moderno. El autorretrato lo encontrará Rebecca como parte de una obra breve, Tre volte all'alba, de solo tres capítulos, una obra rara y curiosa, le dice el estudioso de literatura al que va a consultar:

[...] l'avevano trovato tra le carte di un vecchio maestro di musica, un indiano che era morto qualche anno prima. A nessuno risultava che avesse mai scritto alcunché, ma spuntò fuori quella specie di racconto. Lo trovarono bello e lo pubblicarono, sarà un paio di anni fa. Ma un migliaio di copie, anche meno. Una cosa di nulla. (Baricco 2011: 143)

Esta vez Rebecca no tiene ninguna duda, es otra obra de Jasper Gwyn, para la que utiliza un heterónimo distinto además del expediente clásico de que el texto había aparecido escrito en una lengua extranjera, en hindi, y que posteriormente había sido traducido. La dedicatoria del breve libro le da la certeza absoluta de que no se equivoca en su suposición: «A Caterina de' Medici e al maestro di Camden Town». Jasper Gwyn cierra así el círculo y le regala todas las respuestas que le había negado cuando estaban juntos. Pero Baricco todavía no ha terminado, todavía nos reserva otra sorpresa, aunque esta vez tenemos que cerrar la obra que tenemos entre las manos. Seis meses después de la publicación de esta novela, apareció en el mercado Tre volte all'alba, con una nota inicial en la que el autor explica a sus lectores que le ha sido imposible resistirse a la tentación de escribir el libro del que se hablaba en Mr Gwyn y cumplir así el deseo de su personaje de ser conocido a través de su autorretrato.

Jasper Gwyn seguirá publicando desde un lugar desconocido para sus lectores y desde los pseudónimos tras los que se esconde. Su última obra será la investigación de un meteorólogo que estudia la relación entre el tiempo y las vidas de las personas de un pequeño pueblo danés. El final del trabajo del meteorólogo coincide con el final de la novela, al tiempo que nos lleva una vez más hasta Seta y a los últimos días de Hervé Joncour: «A qualche pagina dalla fine muore, in una giornata di vento freddo, dopo una notte di stelle» (Baricco 2011: 158). 
Por nuestra parte, para concluir este trabajo, citaremos de nuevo las palabras de Lotman: «La elección, por parte del escritor, de un determinado género, estilo o tendencia artística supone asimismo una elección del lenguaje en el que piensa hablar con el lector» (Lotman 1970 [1982: 30]). Baricco elige para hablar con los lectores el lenguaje del arte, de la belleza y de la armonía; y para ello crea su propio género y su propio estilo: uno en el que todos los códigos estéticos se unen en una forma de expresión nueva.

\section{REFERENCIAS BIBLIOGRÁFICAS}

BARICCO, Alessandro. (1991): Castelli di rabbia, Milán, Rizzoli.

BARICCO, Alessandro. (1994): Novecento, Milán, Feltrinelli.

BARICCO, Alessandro. (1996): Seta, Milán, Rizzoli.

BARICCO, Alessandro. (1999): City, Milán, Rizzoli.

BARICCO, Alessandro. (2005): Questa storia, Roma, Fandango.

BARICCO, Alessandro. (2006): I Barbari, Roma, Fandango.

BARICCO, Alessandro. (2011): Mr Gwyn, Milán, Feltrinelli.

BARICCO, Alessandro. (2012): Tre volte all'alba, Milán, Feltrinelli.

BozAL, Valeriano. (1987): Mímesis: las imágenes y las cosas, Madrid, Visor.

CALVINO, Italo. (1993 [1973]): Le città invisibili, Milán, Mondadori.

CALVINO, Italo. (1985): Lezioni americane. Sei proposte per il prossimo millennio, Turín, Einaudi.

CESERANI, Remo. (2004 [2003]): Introducción a los estudios literarios, Barcelona, Crítica.

Gaglione, Paola / CASSINI, Marco. (1997): Conversazione con Antonio Tabucchi. Dove va il romanzo?, Roma/Milán, Nuova Omicron.

FouCAULT, Michel. (2010 [1966]): Las palabras y las cosas. Una arqueología de las ciencias humanas, Méjico, Siglo XXI.

InNENARITY, Daniel. (2008): Ética de la hospitalidad, Barcelona, Península.

JAMESON, Fredric. (1996 [1984]): Teorías de la postmodernidad, Madrid, Trotta.

LA PORTA, Filippo. (1995): La nuova narrativa italiana. Travestimenti e stili difine secolo, Turín, Bollati Boringhieri

LOTM AN, Yuri. (1982 [1970]): La estructura del texto artístico, Madrid, Istmo

MARotTA, Karina. (1993): «Cartas desde España», en Jo Heijnen (ed.), A Painters Memory. Catálogo de la exposición y textos críticos; editado por el propio autor.

MAROTTA, Karina. (2007): Jo Heijnen. Unas notas, <www.joheihnen.com/documents/>. PANZIERI, Fulvio. (1996): «Variazioni da un'anticamera postmoderna. Scenari \& trend della narrativa italiana tra anni Ottanta e Novanta», en Raffaele Cardone / Franco Galato / Furio Panzieri (eds.), Altre storie, Milán, Marcos y Marcos, pp. $15-52$ 
PIERSANTI, Claudio. (1989): «Un compagno di viaggio», en Vittorio Coletti (ed.), Sul racconto, Bolonia, Il lavoro editoriale, pp. 85-90.

STEMPEL, Karin. (2000): «Plugging the Base Fields», en Michael Fehr (ed.), Die Farbe hat mich, Essen, Klartext, pp. 90-93.

VATTIMO, Gianni. (1994 [1990]) «Posmodernidad: ¿una sociedad transparente?», Gianni Vattimo et al., En torno a la posmodernidad, Barcelona, Anthropos, pp. 7-19. 